\title{
UNRHYMED MODERNITY: NEWYORK CITY, THE POPULAR NEWSPAPER PAGE, AND THE FORMS OF WHITMAN'S POETRY
}

\author{
SiMON PARKER
}

WhITMAN TOOK, as we might expect, close interest in the final stages of production of the first edition of Leaves of Grass. However, as Gay Wilson Allen observes, his involvement extended beyond that of authorial approval of work commissioned, to participation in the practicalities of printing the book:

The two Rome brothers, James and Thomas, who ran a good printing shop on the corner of Fulton and Cranberry, were friends of [Whitman], and they printed books, though mainly legal works. They were not only willing to print the book but would let Walt supervise the work, even set some of the type himself-and he did set about ten pages. There at the Rome Brothers' printing office nearly every morning during the spring of 1855 the poet sat in his special chair in the corner. First he would read the morning Tribune and then he would correct proofs for a few hours. ${ }^{1}$

What we see again and again with Whitman is the combination of activities - writing poetry is mingled with reading the newspaper and an active interest in the technicalities of printing (Whitman trained as a printer before he became a journalist and poet). In his notebooks of the 1840 s and 1850 s, and into the 1860 s, we see much more than an artist impatient with the mundane demands of journalism; rather we see a Whitman who merges his drafting of the poems with an interest in all aspects of the newspaper. In the notebooks, Whitman often seems to mix poem fragments with copied newspaper classified columns; as Fredson Bowers has noted:

the heavily revised draft of what was to become part of the [1860] "Calamus" No. 2 was written on the back of paper which had previously been used to rough out in pencil the draft for what seems to be a proposed editorial on the Brooklyn Waterworks for the Brooklyn Daily Times, of which Whitman was then editor. ${ }^{2}$

We see here not simply a poet who wrote literary reviews and cultural essays for the newspapers, but a poet who was interested in typesetting, classified advertising, and plumbing together with his poetry. Many critics have considered the way in which Whitman borrowed the content of 
newspaper editorials and reports for the subjects of his poetry-police court reports, suicides, prostitutes, and firemen. However, I am suggesting that the relationship between Whitman's vision and the whole range of developing features of the cheap daily newspaper is much more intimate and coherent than that. By examining the first edition of Leaves of Grass in relation to the New York newspapers' developments in form as well as content, we will see that the newspaper offered to the midcentury Whitman the basis of an original and substantial vocabulary with which to portray and explore the developing modern city. Whitman was a poet concerned with seeing, as he said in the 1855 preface, "the solid and beautiful forms of the future where there are now no solid forms"; 3 and he also had considerable experience as an editor and a printer. The new cheap newspapers provided a framework or lens through which to see and describe an urban environment without precedent in literature.

Between 1840 and 1860 Whitman had substantial experience as a newspaper printer, editor, and reporter. Like other American journalists of the time, it was to the leading New York City newspapers that he turned for a model of the best (and sometimes the worst) developments in mass popular newspaper publishing. During the period of Whitman's work as a newspaper editor, "the Herald was the most emulated newspaper in America," having been at the forefront of a revolution in the New York cheap daily newspaper press. ${ }^{4}$ In terms of scale, circulation for the city's newspapers rose from under 10,000 in 1830 to six figures in 1860. Circulation of the biggest individual daily papers rose equally sharply: for example, by 1853, the New York Herald claimed a daily circulation of $52,000 .^{5}$ The nature of the reader also changed, from that of specialized consumer of commercial information or partisan rhetoric to a much more general audience, united less by special interest than by common experience of the city. On several occasions Whitman the editor commented on such changes. In the July 31, 1858, Brooklyn Daily Times he wrote:

The great daily journals have a department for all. The business man glances anxiously at his own corner of the sheet to mark the quotations of stock or the fluctuations of trade; the literature [littérateur] turns to his own particular column for reviews or announcements of new books; the people who are anxious about absent friends, to their appropriate departments; the unemployed, to the column of wants; and everybody to the telegraphic head, which is glanced at as anxiously each morning by millions of readers as if it held the fate of each. ${ }^{6}$

In various prose statements Whitman talked of the newspaper as an essential shared modern experience: again in the Brooklyn Daily Times, he wrote, "What was once deemed a luxury, and a somewhat superfluous one at that, is now a matter of necessity no more to be dispensed 
with than one's breakfast"(39). And it wasn't only in the editorials that he promoted the idea of the newspaper in this way. In the appendix to the 1856 edition of Leaves of Grass he talked of popular reading matter as "the garments of a generation." Such rhetoric wasn't an invention of Whitman's-it was common to the new editors of the New York popular newspapers, most famously men like James Gordon Bennett Sr. of the Herald, who talked of the editor being "with the common people" as an equal, free from the apparent respectability of a world "humbugged" by the "spouters" of the older specialized press. ${ }^{8}$ Quite clearly, the editors of the new mass circulation daily papers were constructing the city here as a populist democratic space for commercial reasons, appealing to a new market that transcended older class boundaries. Or, to put it another way, the chaotic, unpredictable, and often violent environment that was New York in the 1840s was characterized by the new editors (including Whitman) as the arrival of a democratic spirit valuable because it seemed to undermine old orders, institutions, and hierarchies. Although Whitman, in common with other editors of the 1840 s, sometimes expressed disquiet at the perceived vulgarity of a figure like Bennett-he once described him as a "reptile"-in the main, he voiced enthusiasm for the developments of the popular newspaper, including the Herald. In the January 6, 1846, Brooklyn Eagle, Whitman noted that "we are no admirers of the Herald's flippant, sneering, exclusively selfish and sordid method in the editorial department," but he went on to affirm that

print has done an immense advantage to the American press, in the way of offering it an example of newspaper enterprise and activity. Not until the advent of the Herald did the "Wall Street press" get the wind taken out of its sails; for previous to that time, the cheap papers were purchased because they were cheap; afterwards because they were better. ${ }^{9}$

This preference for the "cheap" over the windier establishment finds clear expression in Whitman's 1855 poems. In "Song of Myself" his democratic poet (described, of course, as "one of the roughs") declares: "I am less the reminder of property or qualities, and more the reminder of life, / [ . . .] And beat the gong of revolt, and stop with fugitives and them that plot and conspire" (49-50). In the newspaper, the obvious instability of the city's identity was represented in the mingling of a new and apparently chaotic range of material - trivial and sensational, highbrow and lowbrow. Verbatim reports of a sermon or committee meeting would sit next to lurid details of a murder or scandal amongst the city's elite, and this would be next to (say) a report on the construction of street lighting, which would be next to classifieds advertising treatments for syphilis. This variety is echoed in Whitman's long poems; in what became Section 15 of "Song of Myself," for example, there is a 
mixture of the sensational ("The malformed limbs are tied to the anatomist's table, / What is removed drops horribly in a pail") and the mundane ("the signpainter is lettering with red and gold") (39-40).

So, what we often see reflected in the poems is the newspapers' rhetoric of openness to "all," a rhetoric that derives from the new editors' conception of the city as a new market, a new, evolving body of readers not bound to the more specialized, party-political or commercial interests of the earlier newspaper. And the tremendous variety of material in the new papers throughout the 1840s and 1850s is typical of what is a period of pioneer development in the mass newspaper market. In contrast, the latter half of the century saw the greater development of newspapers designed to appeal to particular and discrete levels of taste (a market more similar to the newspapers of our own time). But what interests me here is that just as the commercial exploitation of newspaper markets and technology mirrored the rapidly shifting social makeup of the growing city, so does Whitman's poetry represent a similar (though obviously less commercially-oriented) quest for forms and subjects appropriate to the new and radically unpredictable metropolis.

$\mathrm{He}$ approaches his objective, the portrayal of his "vision" of the city, through the medium (the newspaper) in which he learned to write; and this includes the populist democratic rhetoric of the new editors that he adopts in the artistic manifesto that introduces his poems. In the preface to the 1855 Leaves of Grass he asserted:

the genius of the United States is not best or most in its executives or legislatures, nor in its ambassadors or authors or colleges or churches or parlors, nor even in its newspapers or inventors . . . but always most in the common people. (5-6)

He goes on to list randomly the features of these "common people"-a description very like that of the crowds presented in editorial sketches of the city streets-and he declares that "these too are unrhymed poetry. It awaits the gigantic and generous treatment worthy of it"(6). Whitman positions himself - as he was used to doing in his years as an newspaper editor - politically and rhetorically with the new urban working class. He identifies himself as "Walt" rather than Walter and poses in manual worker's clothes in the anonymous daguerreotype portrait that stands in place of the author's name in the first edition of the poems. Like the editors of the major new popular New York papers, he presents himself as a member of, and a spokesman for, this evolving urban class. And it is because the poet also adopts many of the popular newspaper's forms and methods of addressing or describing this new and relatively unknown constituency that the poems of Leaves of Grass often have such a strange appearance. 
As a journalist and printer working within the new cheap newspapers of mid-century New York and Brooklyn, Whitman was familiar not simply with the daily experience of the streets but more specifically with the shapes of the city's popular reading matter. And as he presented his poetic persona and poetry as populist in a manner similar to that of the new editors and major cheap daily papers, so too did he carry some of the forms and appearance of the popular newspaper pages into his poetry. As I mentioned earlier, Whitman's notebooks and manuscripts, as well as his involvement in the final production of the first edition of the poems, suggest that the process of his poetic creativity was closely allied to the newspaper editor's work of combining a variety of clippings from other newspapers with his own thoughts and firsthand reports. The poems take their earliest draft form, indeed their means of creation, within a visual layout which resembles that of a newspaper page. Unlike many of his contemporaries in what we regard as the American Renaissance canon, Whitman was not university-educated. His education after the age of twelve was as an apprentice printer and compositor on small newspapers. As a printer, he had been trained to see language in terms of blocks of type and proofs to be arranged and edited rather than composed. Later, as an editor, Whitman would combine editorial statements with columns of short news items and clippings, advertisements, and commercial and personal announcements. His notebooks suggest that a similar conception of creativity-experiments with the layout of combinations of lists, notes, and brief verses or passages of prose-defined his early drafting of the poems.

Whitman's substantial experience as a printer and newspaper editor meant more than just an opportunity to somehow absorb a collection of experiences of the city which would later be turned into poetry by adding the wayward but essentially literary genius of the artist. On the contrary, evolving elements of newspaper form and page design became essential elements of Whitman's poetic vision of the city. Aspects of the poetry which often seem odd to twentieth-century literary readers were comparatively natural to the mid-nineteenth-century newspaper reader and to the journalist and printer who wrote them.

The development of the cheap daily newspapers in terms of their rhetorical assertion as the shared expression of the common working citizen's experience of New York was matched by innovations in their style and design. A vocabulary of form evolved which included the size and layout of columns and paragraphs, the use of headlines, the use of white space and illustrations, and the sectional divisions within the page. These contemporary developments were reflected in some of the forms Whitman adopted in poetry which, as the 1855 preface declared, aimed to be "transcendent and new" (8). In particular, we note: the use of identical form for wildly different subject matter; and the length of, and degree of repetition within, Whitman's catalogues or lists. 
Much has been written about the deliberate structuring principles at work within the seemingly random catalogues of Leaves of Grass. ${ }^{10}$ However, comparison between the poems and the newspaper page offers further insight into some of the apparent peculiarities of Whitman's use of the form. For example, it is curious that Whitman moves between such extremes of the dramatic and the mundane in his poetic catalogues. On the face of it, it would seem logical that, given his aim to voice what he sees as the poetry inherent in the common fabric of modern America, Whitman would want to show the energies of the "everyday" city by offering up images to outshine the grandest instances of European history and culture. And indeed he does this on many occasions; in "Song of Myself" he matches Kronos, Zeus and Hercules with the city firemen:

Those ahold of fire-engines and hook-and-ladder ropes more to me than the gods of the antique wars,

Minding their voices peal through the crash of destruction,

Their brawny limbs passing safe over charred laths .... their white foreheads whole and unhurt out of the flames. ... (74)

The figure of the fireman appears on a number of occasions in Whitman's poetry (and, of course, in the newspapers - the city was always catching fire), and provides a contemporary Vulcan to eclipse the "antique" gods of the Old World. However, just as often, Whitman offers examples of life in the city which are banal. For example, elsewhere in the same poem the images are not, how shall we say, quite as thrilling:

On the piazza walk five friendly matrons with twined arms;

The crew of the fish-smack pack repeated layers of halibut in the hold,

The fare collector goes through the train-he gives notice by the jingling of loose change,

The floormen are laying the floor-the tinners are tinning the roof-the masons are calling for mortar. ... (41)

These are not occasional failures and many of Whitman's long poems contain similarly routine material. Furthermore, the extraordinary and the ordinary are presented in similar form - both are contained within the larger lists. It may of course be argued that the paucity of sophistication within so many of the items in the poems is essential to Whitman's wider point: they are prosaic yet, "en masse," significant because they are all equal parts of the common life of the city. However, the use of uniform layout for (what seem to us) very different kinds of image or story also forms much of the page in the mid-century New York newspaper. Consider this example from the January 10, 1850, New York Tribune. In the news column, two short items are given equal space, in 
the same column, with the same weight of headline. The first is a crime story:

IMPORTANT ARREST-Stephen W. Foster was arrested or gave himself up to officer Bowyer this morning on a charge of passing a spurious Five Hundred Dollar Bill of the Merchants and Traders Bank of this City upon Mr Josiah B. Colgate. . . Foster came into the office and asked $\mathrm{Mr}$ Colgate if he had any gold. He said he had. Foster then said he would take $\$ 500$ and handed the bill in exchange. . . . Foster remarked, "I suppose gold is the best thing I can take to California". ... By means of a daguerreotype portrait of Foster, Mr Colgate was able to describe him to officer Bowyer, who took the matter in charge, and traced Foster to Boston. His arrest was a matter of certainty, so that he deserves no credit for giving himself up.

Whilst this tale may seem quite tame compared to the screaming headlines of modern tabloid papers, in its detail about the coolness of the criminal and the advanced methods of police detection it is positively thrilling compared to the second item which appears immediately below it:

THE GAS MEETING-Quite a full meeting of the gas consumers was held last night, the subject of prices for gas here and elsewhere discussed, a Committee appointed to draft resolutions, requesting the legislature to select a committee to investigate the affairs of the Gas Companies in this City.... A committee of three were appointed to examine the discovery of a new source of light and report upon it. Another committee of three were then appointed to collect subscriptions to defray the expenses of this movement; while the meeting adjourned to meet again on Wednesday evening next, at the same time and place.

If this item made it into the Tribune's weekly edition it might have been read by upwards of 200,000 people. But interestingly, there is little attempt to use design or style to distinguish one story from the other.

A similar merging together of what might seem to us a rather striking range of subject matter often went on in the telegraphic news columns. Under the heading of "Intelligence by the Mails: Philadelphia Correspondence," the July 7, 1849, New York Herald offered the following, again using a uniform size of type and layout:

The cholera cases have diminished today to 19 cases and 3 deaths in private practice, and 15 cases and 9 deaths at the alms-house, county prison, and hospital, making a total of 34 cases and 9 deaths.

Two individuals, F.Z.C. Judson of New York and Ned McGowan of Moayamensing, had a recontre in the city a few days since, in which the latter severely battered the former.

Mr Frederick A. Packard has been elected President of the Girard College.

Cornelius Brannon is lying at the hospital in a very dangerous condition from a stab inflicted in an affray at Ninth and Market Street.

The flour market continues firm, and holders have advanced their rates to $\$ 4.50$ for shipping brands. 
So within a column where the items all look the same we have an epidemic, a street fight, an attempted murder, and the price of flour. Whitman's notion of the poet's relationship with "the common people" of the city very often takes its visual form from the overall appearance of the newspaper page. As the newspaper editorial comment lay between columns like the ones described, so does Whitman's poet speak between similar sets of miscellaneous enumeration. Whitman's catalogues quite often feature this kind of uniform listing with little or no indication of relative importance or unimportance. In the poem "A Song for Occupations," Whitman maintains the same form of description throughout a long list of items (lines 119-158). Although this catalogue begins to introduce some sense of movement within its items (for example, "the upper cut and one-two-three" [97]), in most respects it offers a treatment of miscellaneous subjects that is if anything even more uniform than that found in the newspaper examples. With a few exceptions, lines 119-158 of this poem begin with the definite article. Now in one sense this repetition emphasizes Whitman's "democratic vision" outlined in the earlier poems of the volume since all the items are shown to be of equal importance. But it also causes the catalogue to resemble those columns of the newspaper which are most repetitive in appearance- that is, the classified advertising columns. Whitman perhaps draws attention to this fact in line 154: "The column of wants in the one-cent paper .. the news by telegraph .... the amusements and operas and shows" (97).

Now having said this, whilst we may understand Whitman's notion of a democratic naming of "all" the "common" features of city life, we might nevertheless ask why the lists are so long and so repetitive. I suspect that many of us, when first reading Whitman's long poems, have been tempted to skip through a lot of the catalogues to find some "formula" at the end, a shortcut which often seems to be rewarded. For example, in "A Song for Occupations," the list is concluded with "In them your themes and hints and provokers"(98). And many readers have found them to be very provoking. But Whitman is not simply listing in a uniform manner the common "experiences" of the city. Rather he is seeing and reproducing the city through a form in which he first learned to write about it and through which the new urban newspaper reader would expect to see it. We may not entirely understand his apparent fascination with the classified advertising of the newspaper-such as the way in which he seemed to copy advertisements in his notebooks, interspersed with sketches of poems. But Whitman and his contemporary readers were nonetheless interested. Newspaper editors recognized the desirability of fresh advertisements: the advertising columns in the Herald were headed "Advertisements Renewed Every Day," and Bennett claimed that advertising columns were news. ${ }^{11}$ Further, some historians have suggested that the classified advertising columns, with (in the $\mathrm{Her}$ - 
ald) their uniform agate type, offered a vital and democratic window on city life by virtue of being open to all who could buy the newspaper or pay the advertising rate. ${ }^{12}$

Whitman's poetic vision of the common facts of city life often presents an outward shape similar to that of the advertising column. The overall appearance of those two pages of the "Song for Occupations" poem discussed above bears similarities to the advertising in the columns of the newspaper page. The classified advertising columns in the Herald of the 1840 s and 1850 s appeared as unbroken lists of equallysized items running the length of three to six columns across the page. In the classified advertising column as in the poem, the beginning of each item emphasized the uniformity-commonly by the repeated use of a large-type upper-case initial letter, establishing a continuity between the different sections of the classifieds (Wanted, Removing, Ice, Dry Goods, Boarding, Doctor). As with Whitman's poetic catalogues, the different items are of uniform size and color (shade of grey, quantity of white space). Similarly, lists of commercial announcements in the newspaper page were often highlighted by using repeated small graphic illustrations of houses, hats, and ships. Whilst Whitman's poems obviously don't use these graphics, his notebooks do use such motifs (especially the pointing finger) as a marker for the miscellaneous addresses, advertisements, laundry lists, and for drafts of poems. In "Song of Myself," Whitman wrote:

This is the city .... and I am one of the citizens;

Whatever interests the rest interests me .... politics, churches, newspapers, schools, Benevolent societies, improvements, banks, tariffs, steamships, factories, markets, Stocks and stores and real estate and personal estate. (76)

Much criticism has looked at the way Whitman's work with popular publishing formed the basis of his response to the unpredictable variety of the city-he has been seen to write a transcendental vision that rises above, or transforms, or somehow transfigures the city's culture. But examining the rhetoric and forms of the biggest developing mass daily newspapers in mid-century New York suggests that Whitman's vision of the city was not entirely (or merely) an urban rendering of New England Transcendentalism. On the contrary, a comparison between the forms of the newspaper and those of the first edition of Leaves of Grass may indicate that far from the city being a chaotic mess waiting to be healed by the ahistorical forces of art and nature, it in fact generated languages of its own (albeit, ones not always amenable to our literary tastes and expectations). From this perspective, we might begin to consider whether Whitman's modernity derives not from his iconoclasm per se but from a sustained engagement or even adoption of these languages of the city in a particular time and circumstance. 
In the preface to the 1855 poems, his populist celebration of the "common people" asserts that "to be is just as great as to perceive or tell" (17) and goes on to describe, in general terms, the favored form of his modern democratic poet:

The greatest poet has less a marked style and is more the channel of thoughts and things without increase or diminution [. . . .] I will not be meddlesome, I will not have in my writing any elegance or effect or originality to hang in the way between me and the rest like curtains. I will have nothing hang in the way, not the richest curtains. What I tell I tell for precisely what it is. [. . .] What I experience or portray shall go from my composition without a shred of my composition. (14)

Now Whitman is calling here for a free "channel" for the things of the New World, one without the mediating hand of the author. The machine of the modern city, the steam-driven press producing a mass medium shared (in theory) by "all," presented to Whitman the printer and editor a model of this form. The modern rotary press continued to require column rules to hold in the type during printing, creating the uniform columns that were the "channels" ready to be filled with the diverse objects and events of the changing city. Whitman aimed to envision the American city as an endless process of becoming, formless yet formed-and he found an early form for achieving this in the shape of the newspaper page, changing daily, yet regular in overall layout.

\section{Lancaster University}

\section{NOTES}

1 Gay Wilson Allen, The Solitary Singer: A Critical Biography of Walt Whitman (New York: New York University Press, 1967), 147-148.

2 Fredson Bowers, Whitman's Manuscripts, Leaves of Grass (1860): A Parallel Text (Chicago: Chicago University Press, 1955), xxvii-xxviii.

3 Walt Whitman, Collected Poetry and Collected Prose, ed. Justin Kaplan (New York: Library of America, 1982), 8.

4 James L. Crouthamel, Bennett's New York Herald and the Rise of the Popular Press (Syracuse: Syracuse University Press, New York, 1989), 54.

5 Crouthamel, 54.

6 Emory Holloway and Vernolian Schwarz, eds., I Sit and Look Out: Editorials From the Brooklyn Daily Times by Walt Whitman (1920; rpt. New York: AMS Press, 1966), 39.

7 Kaplan, 1329.

8 Frank L. Mott, American fournalism: A History of Newspapers in the United States Through 250 Years, 1690-1940 (New York: Macmillan, 1941), 232.

9 Thomas L. Brasher, Whitman as Editor of the Brooklyn Daily Eagle (Detroit: Wayne State University Press, 1970), 36. 
10 See, for example, discussions in Lawrence Buell, Literary Transcendentalism: Style and Vision in the American Renaissance (Ithaca: Cornell University Press, 1973); Michael D. Reed, "First Person Persona and the Catalogue in 'Song of Myself," Walt Whitman Review 23 (1977), 147-155; Donez Xiques, "Whitman's Catalogues and the Preface to Leaves of Grass," Walt Whitman Review 23 (1977), 68-76.

11 Crouthamel, 52.

12 Michael Schudson, Discovering the News: A Social History of American Newspapers (New York: Basic Books, 1978), 19. 